\title{
Research on Energy Management Method of Plug-In Hybrid Electric Vehicle Based on Travel Characteristic Prediction
}

\author{
Yangyang Ma ${ }^{1}$, Pengyu Wang ${ }^{1,2}$ and Tianjun Sun $1,2, *$ (D) \\ 1 College of Automotive Engineering, Jilin University, Changchun 130012, China; \\ yyma20@mails.jlu.edu.cn (Y.M.); wangpy@jlu.edu.cn (P.W.) \\ 2 State Key Laboratory of Automotive Simulation and Control, Jilin University, Changchun 130012, China \\ * Correspondence: sun_ti@jlu.edu.cn
}

Citation: Ma, Y.; Wang, P.; Sun, T. Research on Energy Management Method of Plug-In Hybrid Electric Vehicle Based on Travel Characteristic Prediction. Energies 2021, 14, 6134. https://doi.org/10.3390/en14196134

Academic Editor: Ahmed Abu-Siada

Received: 29 August 2021

Accepted: 24 September 2021

Published: 26 September 2021

Publisher's Note: MDPI stays neutral with regard to jurisdictional claims in published maps and institutional affiliations.

Copyright: (c) 2021 by the authors. Licensee MDPI, Basel, Switzerland. This article is an open access article distributed under the terms and conditions of the Creative Commons Attribution (CC BY) license (https:// creativecommons.org/licenses/by/ $4.0 /)$.

\begin{abstract}
In the research on energy management methods of plug-in hybrid electric vehicles, it is expected that a future trend will be to optimize energy management using the information provided by the global positioning system (GPS) and intelligent transportation system (ITS), which is relatively scarce in current research. This study proposes a PHEV energy management method based on travel characteristic prediction. Firstly, this study processes the historical travel data of a certain driver obtained by GPS and ITS and uses the established Markov trajectory prediction model based on key points to predict the trajectory and mileage. Then, on the basis of characteristics analysis of historical travel data, while considering traffic information to form a target cycle, the driving cycles are classified and identified based on traffic information predictions. Then, according to the reasonable SOC allocation range of the four typical cycles, the planning algorithm of the SOC reference trajectory is determined and verified. Finally, based on the previous work, an A-ECMS energy management method based on travel characteristic prediction is established. By comparing different energy management methods, the developed energy management method based on travel characteristic prediction can reasonably utilize power batteries. The fuel saving is about $8.95 \%$ higher than the rule-based energy management method, which can effectively improve the whole vehicle's fuel economy and optimization ability.
\end{abstract}

Keywords: plug-in hybrid electric vehicle; travel characteristics; prediction; energy management method

\section{Introduction}

The energy crisis and environmental pollution are the main problems facing the world [1]. Governments and research institutes all over the world are paying attention to green renewable energy sources. Battery electric vehicles have developed rapidly due to their use of green and renewable energy, but the battery technology has not broken through the performance bottleneck, the needed infrastructure has not yet been completed and other factors have restricted the popularity of battery electric vehicles (BEVs) [2]. Plug-in hybrid electric vehicles (PHEVs) can both use electric energy and fuel, which can effectively alleviate the energy crisis and reduce emissions. Compared with hybrid electric vehicles and battery electric vehicles, PHEVs have important development significance [3].

At present, the rapid development of information and communication technologies (ICTs) provide lots of data, which we call big data [4]. The use of big data can facilitate the establishment and verification of transport system models (TSM). A big-data analysis method for estimating the driving range of an electric vehicle $(\mathrm{EV})$ is proposed in [5]. In reference [6], a method for on-street parking search time based on floating vehicle data (FCD) is proposed. The proposed method can be used both in real time to support user information and evaluate traffic plans offline. Intelligent transportation systems (ITS) will also produce a large amount of data [7], which can be helpful to the road traffic flow prediction and personal travel route plan, etc. The global positioning system (GPS) and intelligent transportation system (ITS) can provide the big data for the prediction. 
The main goal of PHEV control is to reduce comprehensive energy consumption and reduce air pollution [8]. The main means of PHEV control is to use energy management strategies (EMS) to meet the driver's power requirements and limit the short-term power consumption of the battery within a certain range, so as to minimize the overall fuel consumption of the vehicle [9]. The rule-based and optimal energy management strategy are the main energy management strategy of plug-in hybrid electric vehicle [10]. In references [11,12], rule-based energy management strategy for PHEV is introduced in detail, such as charge depleting-charge sustaining strategy (CD-CS) [13], etc. However, rule-based energy management strategies are usually decided by engineering experience and working mode [14] and rule-based energy management strategies are often subjective and cannot fully adapt to the change of working conditions and dynamic response. Based on the optimal energy management strategy, a global optimal solution can be obtained, such as dynamic programming (DP) [15,16] and Pontryagin's minimum principle (PMP) $[17,18]$. Equivalent consumption minimization strategy (ECMS) is an instantaneous optimization algorithm based on optimal control [19]. It is practical but sacrifices the optimal control performance, and the selection of equivalent factor between fuel and electric energy in the algorithm has a great influence on the control performance of ECMS [20,21].

Travel characteristics and state of charge (SOC) reference trajectory can be used as auxiliary information to apply to the optimal energy management for PHEVs. In [22], an energy management strategy based on model predictive control (MPC) combined with speed prediction is proposed and verified in the NEDC. A real-time energy management method for PHEV based on condition identification is proposed and compared with the global optimal value calculated by dynamic programming [23,24]. The SOC reference trajectory is approximately linear under certain travel cycle conditions, but the SOC reference trajectory can deviate from the linear profile under different power requirements [25]. The DP algorithm obtains the optimal SOC consumption trajectory under the travel characteristics, but the DP algorithm needs known condition information and cannot be applied to the actual driving process of vehicles online [26]. However, an achievable and approximately optimal SOC reference trajectory planning algorithm can be designed based on the DP algorithm and compared with the control results of online optimization methods.

The above studies mainly focus on the energy management under standard driving cycle or foreign driving cycle conditions, and do not consider drivers' travel characteristics. Thus, the actual travel cycle in China may be very different from the standard or foreign cycle, and travel characteristics will also significantly affect the energy management ability, which may bring about poor performance. For the sake of getting the approximate optimal control effect and minimal the overall fuel consumption of vehicles, an adaptive equivalent consumption minimization strategy (adaptive ECMs, A-ECMS) based on travel characteristics prediction is established. The travel characteristics and SOC reference trajectory are used to modify the equivalent factor in real time, so that the SOC consumption trajectory can always follow the optimal trajectory.

The main contributions of this paper include: (i) analyzing the driver's historical travel data, and predicting the driver's travel characteristics represented by mileage and cycle, and (ii) establishing a target travel cycle condition prediction method considering traffic information obtained by GPS and ITS to predict the actual travel cycle condition of Chinese roads, and (iii) designing a reasonable SOC reference trajectory planning algorithm to make the SOC consumption trajectory approximately optimal under the travel characteristic prediction, and applying to the A-ECMS based on travel characteristic prediction.

This paper is organized as follows: A travel characteristic prediction method including mileage and cycle is established in Section 2. The SOC trajectory planning based on mileage and cycle is analyzed in Section 3, and the SOC trajectory planning algorithm is proposed, which is verified and compared with the results of DP algorithm. The results and corresponding analysis of the adaptive energy management method for PHEV based on travel characteristic prediction are presented in Section 4. Concluding remarks are given in Section 5. 


\section{Research on Travel Characteristic Prediction}

Travel characteristics include mileage and cycle. Both mileage and cycle can have a great impact on the energy management of PHEV. The mileage (long or short) can determine whether PHEV uses electric energy and the cycle speed (high, medium or low) can affect the high efficiency area utilization rate of engine and average fuel consumption rate of PHEVs.

\subsection{Mileage Prediction Based on Historical Data}

The path and route selection of vehicle traveling is a vehicle routing problem (VRP), that is, how to select the best travel path of a vehicle [27]. In [28], the author provides a standard for travel path and route selection, namely minimum travel time, travel distance, travel cost, and energy consumption. This paper does not consider multiple factors as in literature [28], and the determination of travel path and route depends on the driver. It is worth noting that the travel routes of specific drivers are relatively similar, and the historical travel database of the specific driver can be formed.

Based on GPS technology, the key point data is mined according to the driver's current position, historical travel trajectory and other auxiliary information, and the trajectory prediction model is established based on the key points to dynamically predict the driver's future position and complete the prediction of travel trajectory and mileage. The specific process is as follows:

(I) The GPS equipment is used to obtain the historical driving trajectory data of the vehicle, and the data is preprocessed to form the historical driving trajectory database;

(II) Based on the path clustering algorithm, the starting point clustering and key point mining of each historical driving trajectory in the historical driving trajectory database are carried out, and the prediction model is established based on the key points;

(III) At the beginning of travel, the starting point position information is obtained through GPS, and the travel trajectory is predicted according to the historical trajectory database;

(IV) The current travel trajectory is identified based on key points, and the candidate prediction trajectory is dynamically updated when each key point is passed until the destination is reached, so as to complete the travel mileage prediction.

The starting point and key points of travel trajectory are the key information of trajectory prediction model [29]. In order to avoid the interference of third-party mapping software on the trajectory prediction model, the starting point of the trajectory is firstly clustered, and the key points of the historical trajectory clustered into the same class are mined, so as to complete the cluster analysis of the historical travel trajectory. The clustering of trajectory starting points is very important for the accuracy of trajectory prediction model. Figure 1 shows the trajectory starting point clustering algorithm, and the schematic diagram of key point mining is also given in Figure 2.

Based on the above trajectory starting point clustering, a trajectory prediction model based on markov is established $[30,31]$. Then the key points of the trajectory are mined to form the probability matrix $C$ of the key points:

$$
C=\left[\begin{array}{cccc}
P\left(k_{1,1}\right) & P\left(k_{1,2}\right) & \cdots & P\left(k_{1, n}\right) \\
P\left(k_{2,1}\right) & P\left(k_{2,2}\right) & \cdots & P\left(k_{2, n}\right) \\
\vdots & \vdots & \ddots & \vdots \\
P\left(k_{n, 1}\right) & P\left(k_{n, 2}\right) & \cdots & P\left(k_{n, n}\right)
\end{array}\right]
$$

where $P\left(k_{i, j}\right)$ is the transition probability when the vehicle travels to a certain key point $r=k_{i}$ and the next key point is $r+1=k_{j}$, and:

$$
P\left(k_{i, j}\right)=P\left(r+1=k_{j} \mid r=k_{i}\right)=\frac{N_{k_{i, j}}}{N_{k_{i}}}
$$


where $N_{k_{i}}$ is the number of trajectories that pass through $k_{i}$ in the candidate predicted trajectory; $N_{k_{i, j}}$ is the number of trajectories that pass through key point $k_{i}$ and the next key point that passes through $k_{j}$ in the candidate predicted trajectory.

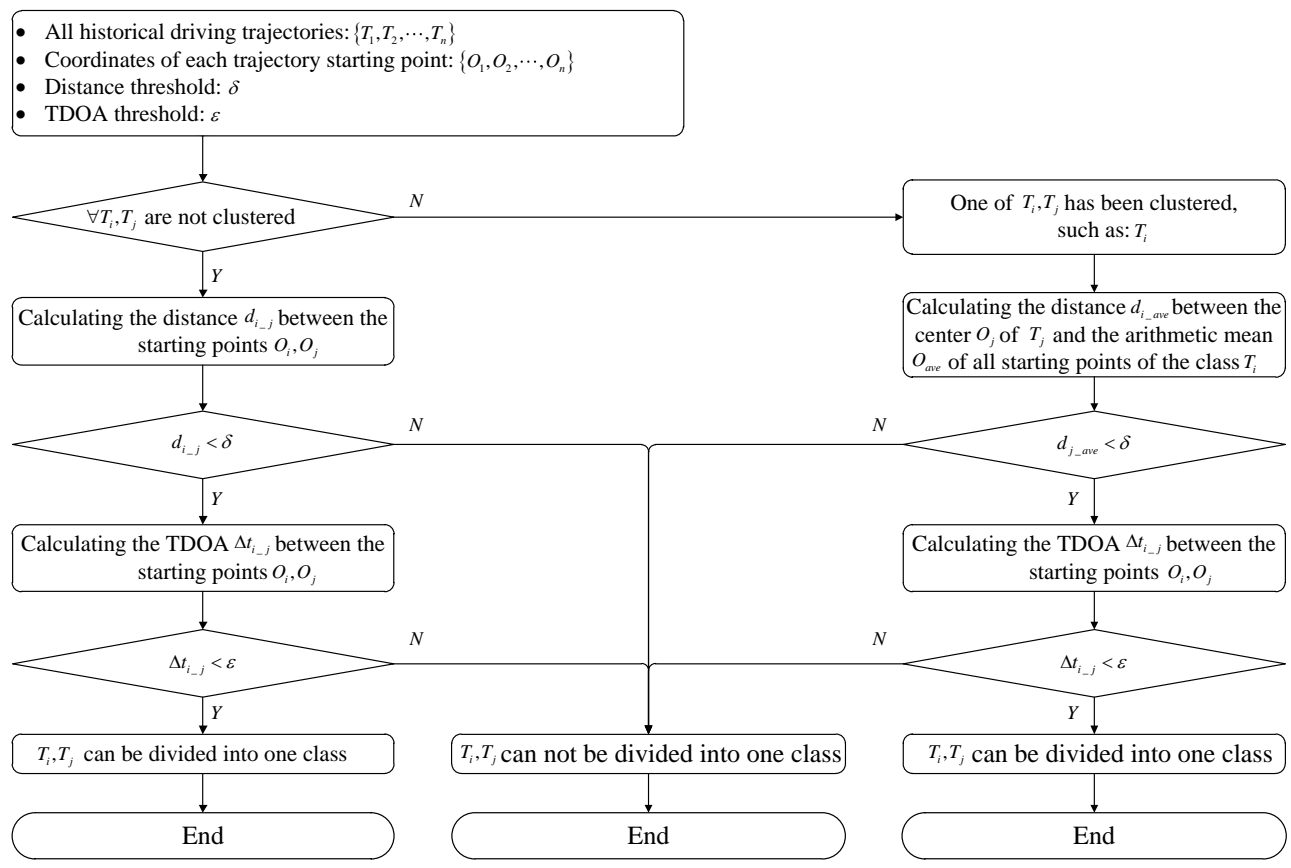

Figure 1. Clustering algorithm for starting point of travel trajectory.



Figure 2. Schematic diagram of key point mining.

If the last key point of the candidate trajectory is known, the travel trajectory of the vehicle can be determined in the candidate trajectory. Assuming that the travel trajectory of this vehicle trip is $T_{p}$, the posterior probability of key point $k_{g}$ is the final key point, which can be obtained by Bayes rule:

$$
P\left(\text { last_key }=k_{g} \mid T_{P}\right)=\frac{P\left(T_{P} \mid \text { last_key }=k_{g}\right) P\left(\text { last_key }=k_{g}\right)}{\sum_{r}^{m} P\left(T_{P} \mid \text { last_key }=k_{r}\right) P\left(\text { last_key }=k_{r}\right)}
$$

where $P\left(\right.$ last_key $\left.=k_{g} \mid T_{P}\right)$ is the prior probability of $k_{r}$ as the last key points of the travel trajectory $(r=1,2,3, \ldots m)$, and the expression is:

$$
P\left(\text { last_key }=k_{g}\right)=N\left(\text { last_key }=k_{g}\right) / N
$$


where $N\left(\right.$ last_key $\left.=k_{g}\right)$ is the number of trajectories that of $k_{g}$ as the last key point, and $N$ is the total number of candidate trajectories.

$P\left(T_{P} \mid\right.$ last_key $\left.=k_{g}\right)$ is the conditional probability that $k_{g}$ is the last key point of the track, and $T_{p}$ is the trajectory of this vehicle travel, which can be calculated as:

$$
P\left(T_{P} \mid \text { last_key }=k_{g}\right)=P\left(T_{P}\right) \times \frac{P_{c \rightarrow g}}{P_{s \rightarrow g}}
$$

where $P_{c \rightarrow g}$ represents the total transfer probability from the current key point $k_{c}$ to the last key point $k_{g}$, and $P_{s \rightarrow g}$ represents the total transfer probability from the starting point $k_{s}$ of the trajectory to the last key point $k_{g} . P\left(T_{P}\right)$ represents the continuous product of the transfer probabilities of point pairs on the trajectory, namely the trajectory probability of traveling along the trajectory:

$$
P\left(T_{P}\right)=\prod_{r=1}^{m} P\left(k_{r, r+1}\right)
$$

With the probability of each key point on the travel trajectory obtained above, the travel trajectory can be predicted by the set of key points with the maximum probability. During driving, the prediction results will be updated every time the vehicle passes a key point to better fit the travel trajectory. At the same time, the vehicle's trajectory will be recorded in the historical travel database to update the database gradually. The above prediction of driving path has been obtained, combined with the longitude, latitude, speed and other information provided by GPS, the mileage information of each time in the driving process can be obtained, and then the mileage information of the whole driving route can be obtained.

\subsection{Cycle Prediction Based on GPS and ITS}

\subsubsection{Target Travel Cycle Prediction Considering Traffic Information}

In the actual travel process of vehicles, the traffic cycle can be predicted in advance with the help of GPS, ITS, etc. The traffic simulation environment is built according to the real travel conditions collected by specific drivers mentioned above, and the real road network design is referred to as much as possible. The actual collected travel route is about $15.2 \mathrm{~km}$ long in this paper. The whole travel is divided into 76 road sections with $200 \mathrm{~m}$ as a unit to obtain traffic flow information. The average traffic flow speed of each road section can be calculated by Equation (7):

$$
V_{\text {ave }(i)}(t)=\frac{\sum_{k=1}^{N} V_{k}^{a v e(i)}(t)}{N}(i=1,2, \cdots, 76)
$$

where $V_{\text {ave }(i)}(t)$ is the average speed of section $i$ at time $t ; V_{k}^{a v e(i)}(t)$ is the average speed of the $k$ th vehicle passing the section at time $t ; N$ is the total vehicles recorded on the road section at that moment.

Based on the above method, the route to the destination and vehicle flow speed information can be obtained with the help of GPS and ITS, and the Mileage-Average speed information of each road section can be obtained, as shown in Figure 3a. Then, according to the formula $T_{\text {ave }(i)}=L_{\text {ave }(i)} / V_{\text {ave }(i)}(i=1,2, \cdots, 76)\left(L_{\text {ave }(i)}\right.$ is the length of $i$ section and $T_{\text {ave }(i)}$ is the time passing through $i$ section), the mileage-average speed information is transformed into time-average speed information (Figure 3b). Finally, the Lowess filter function is used to process the time-average speed curve to obtain the actual road cycle prediction curve in China, as shown in Figure 3c. 

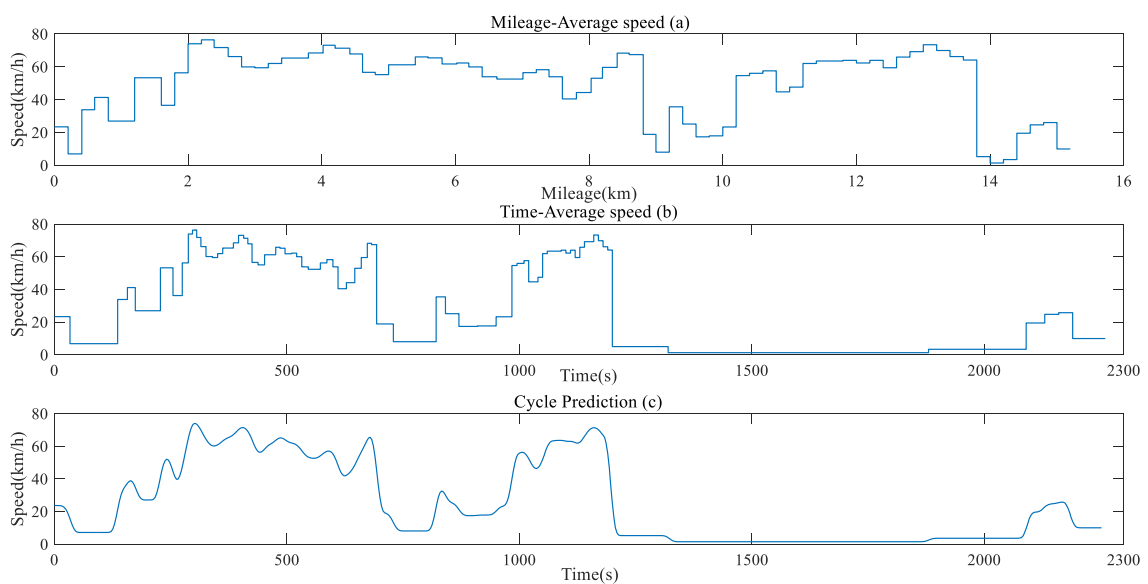

Figure 3. Target travel cycle prediction considering traffic information. (a) Mileage-average speed information; (b) Time-average speed information; (c) Actual road cycle prediction curve in China.

\subsubsection{Cycle Classification and Identification}

Through the analysis of a large number of real road condition data of drivers, and the clustering algorithm is used to cluster the obtained real road conditions according to the characteristic parameters (such as average speed, maximum speed, idle ratio and standard deviation of speed, etc.), four types of typical driving cycle segments are obtained, as shown in Figure $4 a-d$, which respectively represent congested roads in urban areas, relatively unobstructed roads in urban areas, unobstructed roads and expressways in the urban area.
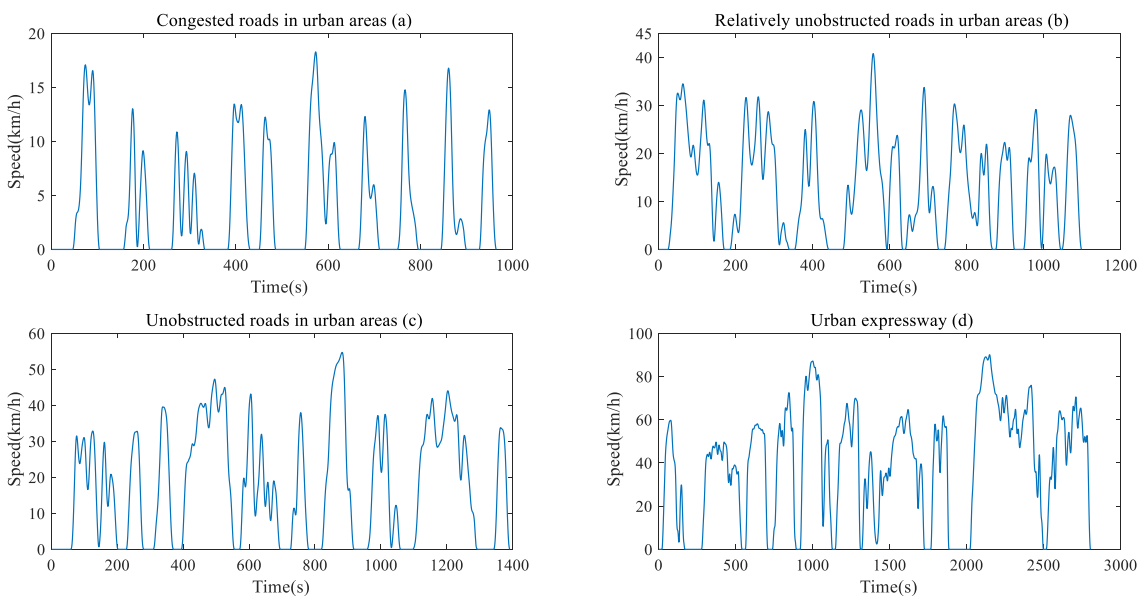

Figure 4. Four typical driving cycle curves. (a) Low speed cycle; (b) Medium speed ccycle; (c) Medium and high speed cycle; (d) High speed cycle.

According to the above prediction method considering the target travel conditions of traffic information, a long term (more than $6000 \mathrm{~s}$ ) actual driving cycle condition (Figure 5a) is obtained for the verification of the following SOC trajectory planning algorithm. At the same time, in the driving process, the cycle characteristic parameters in the current identification cycle are extracted, and the clustering algorithm is still used to cluster the characteristic parameters to complete the classification and identification of cycle conditions. The actual driving cycle conditions in Figure 5 a are identified, and Figure $5 \mathbf{b}$ shows the identification results. 

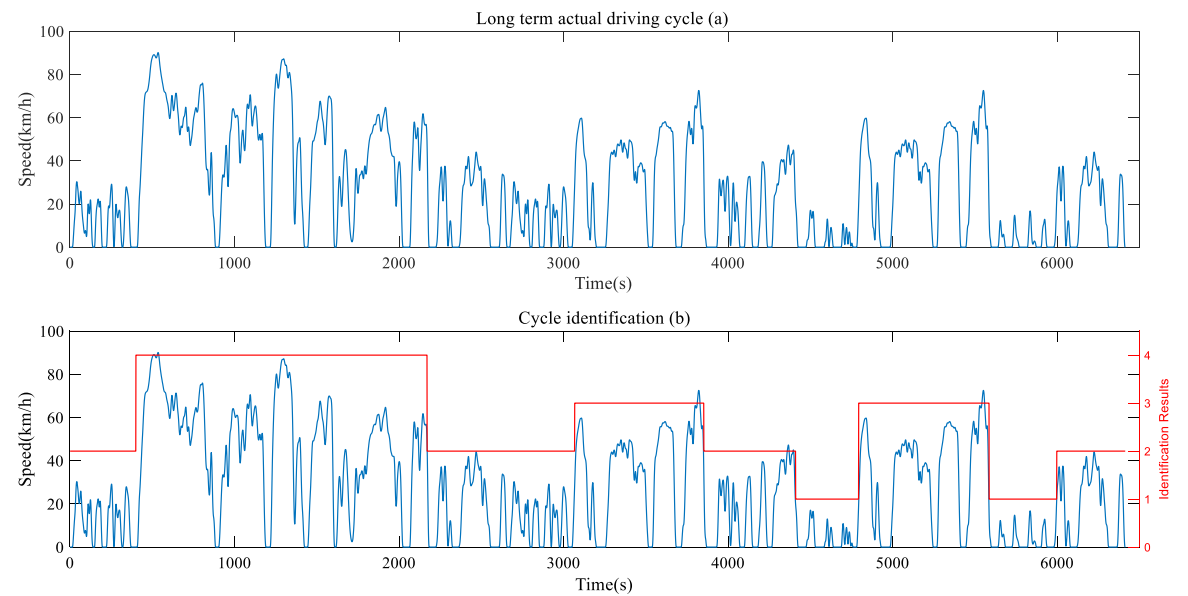

Figure 5. Long term actual driving cycle and cycle identification. (a) Long term actual driving cycle; (b) Cycle identification results.

\section{SOC Reference Trajectory Planning Algorithm}

In this study, a PHEV was used for simulation, and Table 1 shows its main parameters.

Table 1. Main parameters of PHEV.

\begin{tabular}{ccc}
\hline Description & Parameters & Value \\
\hline \multirow{3}{*}{ Basic parameters of the vehicle } & vehicle mass $/ \mathrm{kg}$ & 1568 \\
& frontal area $/ \mathrm{m}^{2}$ & 2.13 \\
& air resistance coefficient & 0.29 \\
& rolling radius $/ \mathrm{m}$ & 0.315 \\
\hline \multirow{2}{*}{ Engine } & peak power $/ \mathrm{kW}$ & 64 \\
& maximum torque $/ \mathrm{N} \cdot \mathrm{m}$ & 203 \\
\hline \multirow{2}{*}{ ISG } & peak power $/ \mathrm{kW}$ & 32 \\
& maximum torque $/ \mathrm{N} \cdot \mathrm{m}$ & 210 \\
\hline \multirow{2}{*}{ Power battery } & capacity $/ \mathrm{A} \cdot \mathrm{h}$ & 40 \\
& rated voltage $/ \mathrm{V}$ & 320 \\
\hline \multirow{2}{*}{ Speed ratio } & transmission speed radio & 1.539 \\
& final drive ratio & 3.944 \\
\hline
\end{tabular}

\subsection{SOC Trajectory Planning Based on Mileage}

Mileage is a key parameter to influence the change rule of the battery SOC [32]. For plug-in hybrid vehicles, if the mileage is known, the battery SOC change trajectory can be designed as a linear SOC trajectory. According to the power consumption of each mileage segment controlled by trajectory, the SOC curve approximate to the DP calculation result can be obtained. This curve is called theoretical SOC reference trajectory [33]. The SOC reference value at any position is calculated as follows:

$$
S O C_{r e f}(s)=\frac{\left(D_{a}-D_{r}(s)\right)}{D_{a}} \cdot\left(S O C_{i}-S O C_{f}\right)+S O C_{f}
$$

where $S O C_{r e f}(s)$ is the $S O C$ reference value at the corresponding position $s$ in the mileage, $D_{a}$ is the total mileage, $D_{r}(s)$ is the mileage traveled at the corresponding position $\mathrm{s}$, and $S O C_{i}$ and $S O C_{f}$ are the initial and final SOC values.

According to Equation (8), when the drivers reach the end of its journey, the SOC trajectory decreases from the initial SOC value to the final SOC value. However, the slope of SOC trajectory change will change with different travel mileage demands. The schematics of theoretical SOC reference trajectory (Figure 6a) and SOC trajectory based on 
DP algorithm (Figure $6 \mathrm{~b}$ ) under $4 *$ NEDC $\sim 8^{*}$ NEDC are shown in Figure 6 . Therefore, the original SOC trend can be improved with the change of travel mileage.
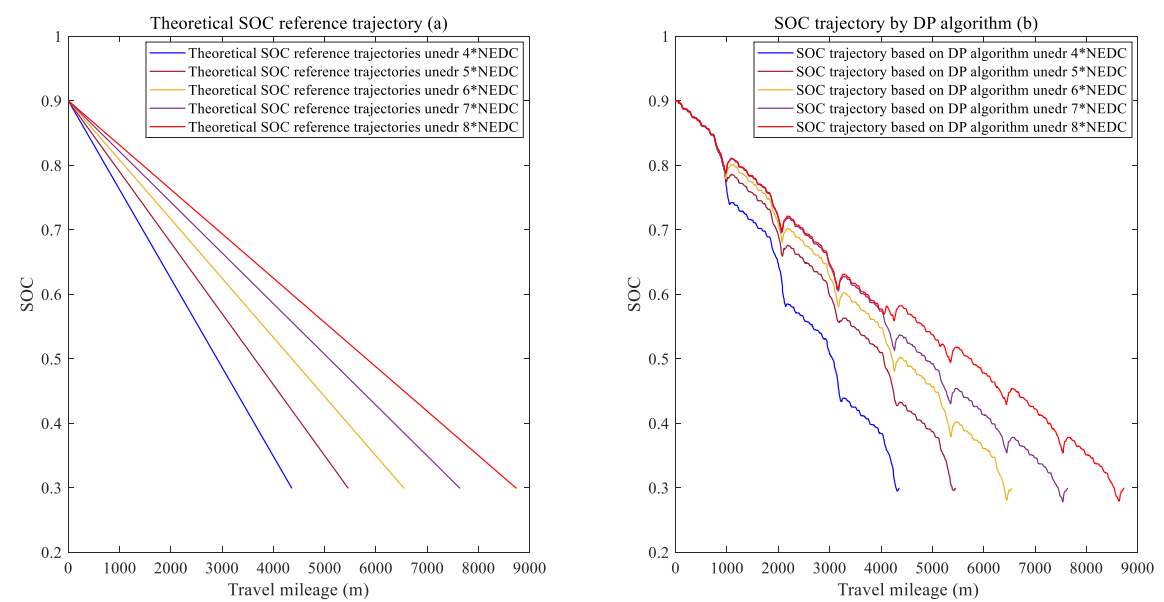

Figure 6. Schematic of SOC planning based on travel mileage. (a) Theoretical SOC reference trajectory; (b) SOC trajectory based on DP algorithm.

\subsection{SOC Trajectory Planning Based on Cycle}

The travel mileages can be used as the basic information of SOC planning, and the driving cycle information can improve the original trend of SOC with mileage, so as to obtain the optimized theoretical SOC reference trajectory, as shown in Figure 7. Figure 7 is only a schematic diagram of SOC trajectory planning based on cycle and does not represent the actual driving cycle.

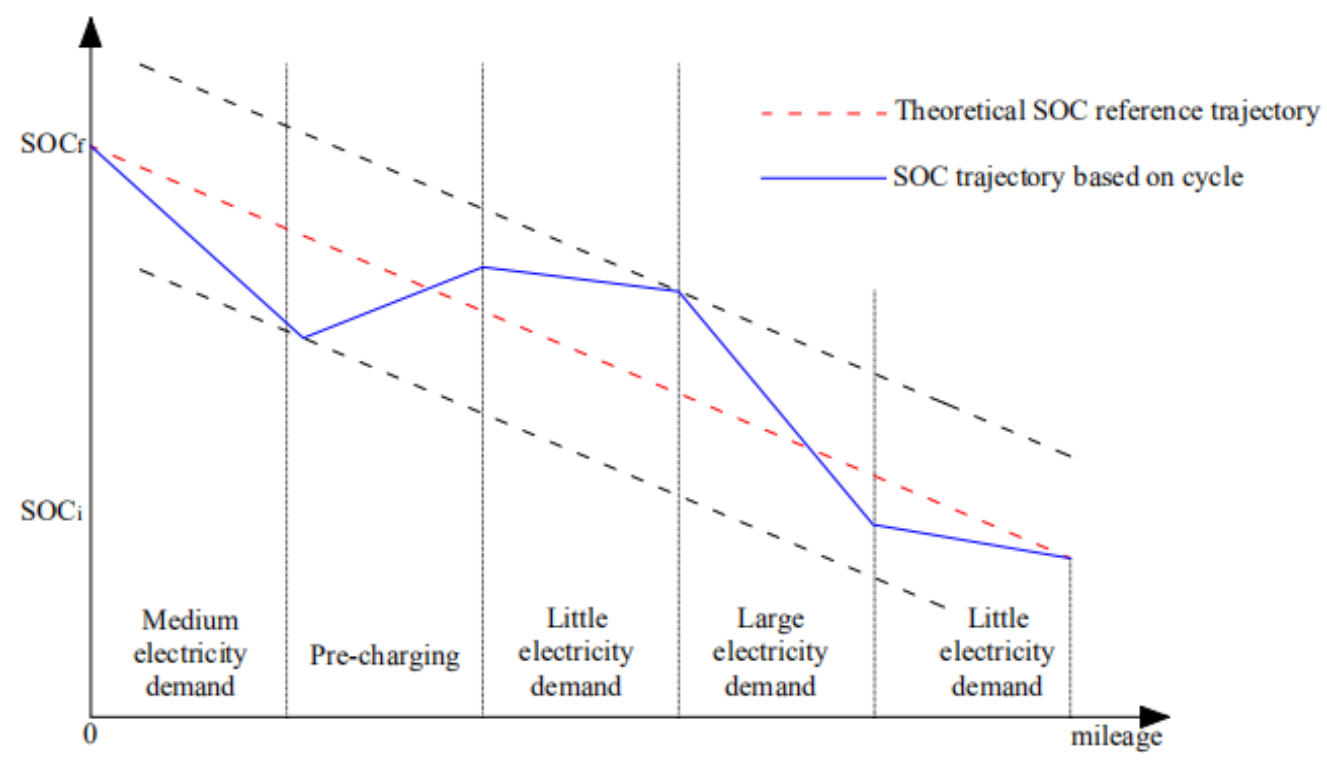

Figure 7. Schematic of SOC planning based on cycle.

Different driving cycles have a great influence on SOC trajectory change, which is mainly reflected in high efficiency area utilization rate of engine and average fuel consumption utilization. Therefore, the following four types of typical cycle identified are calculated and analyzed based on the optimal energy management method of dynamic programming. The relationship between SOC consumption per kilometer and efficiency zone utilization and average fuel consumption utilization is obtained under four typical cycle conditions. 


\subsubsection{Analysis of SOC Consumption under Four Typical Cycles}

The first step is to analyze four typical drive cycles and compare the SOC consumption and fuel consumption per kilometer for different types of typical drive cycles. The objective is to determine the reasonable distribution range of SOC consumption per kilometer in different typical driving cycles. The second step is to consider the difference of characteristic parameters of different driving periods and study the change of SOC consumption per kilometer. The final step is to reasonably plan the SOC consumption per kilometer for each typical driving cycle.

The DP algorithm can calculate the SOC consumption under the driving cycle composed of four typical driving conditions. By setting the initial and final values of SOC in the DP algorithm, the SOC consumption is simulated from low to high until the final SOC value reaches the critical SOC value of the pure electric driving mode under the driving cycle. Thus, the relation curves of SOC consumption per kilometer and high efficiency area utilization rate of engine under four typical cycles are obtained, as shown in Figure 8.
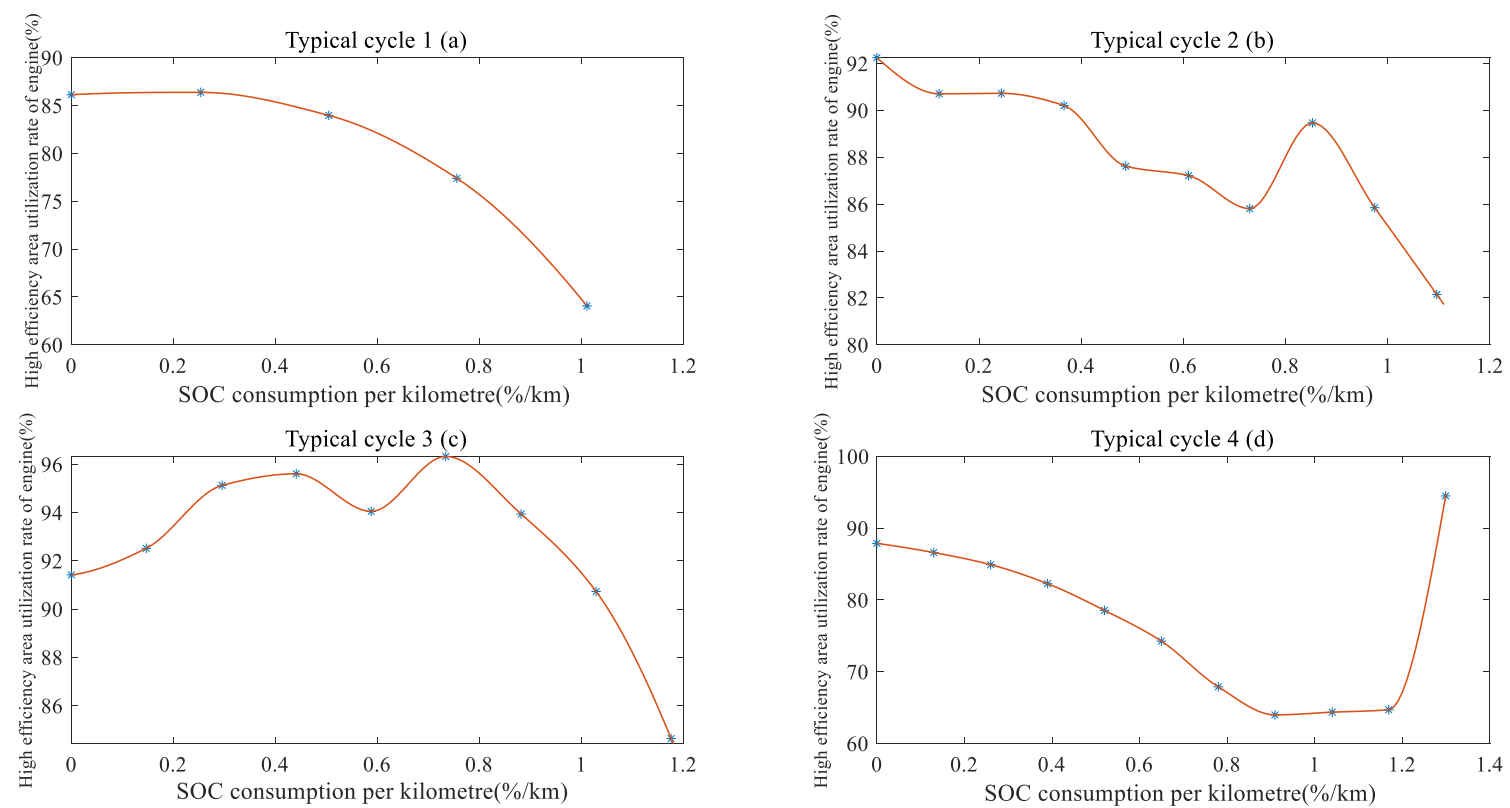

Figure 8. Relationship curve between SOC consumption per kilometer and high efficiency area utilization rate of engine under four typical cycles. (a) typical cycle 1; (b) typical cycle 2; (c) typical cycle 3; (d) typical cycle 4.

At the same time, the relationship between the SOC consumption per kilometer and the average fuel consumption rate $(\mathrm{g} / \mathrm{kW} \cdot \mathrm{h}))$ was also obtained (Figure 9$)$.

According to the relation curve of high efficiency area utilization rate of engine and average fuel consumption rate with SOC consumption per kilometer, reasonable SOC allocation values under four typical cycles can be calculated in SOC trajectory planning. According to the curve relationship shown in Figures 7 and 8, the SOC consumption per kilometer of the vehicle in pure electric mode under four typical cycles can be calculated, as shown in Table 2. At the same time, the distribution upper limit value of SOC under each typical cycles can be obtained, as shown in Table 3.

Table 2. SOC consumption per kilometer in EV mode.

\begin{tabular}{ccccc}
\hline Driving Cycle of Type & $\mathbf{1}$ & $\mathbf{2}$ & $\mathbf{3}$ & $\mathbf{4}$ \\
\hline Maximum SOC consumption per kilometer $(\%)$ & 1.010 & 1.218 & 1.322 & 1.364 \\
\hline
\end{tabular}


Table 3. Reasonable distribution upper limit value of SOC.

\begin{tabular}{ccccc}
\hline Driving Cycle of Type & $\mathbf{1}$ & $\mathbf{2}$ & $\mathbf{3}$ & $\mathbf{4}$ \\
\hline Maximum SOC consumption per kilometer (\%) & 1.010 & 0.871 & 1.175 & 1.299 \\
\hline
\end{tabular}
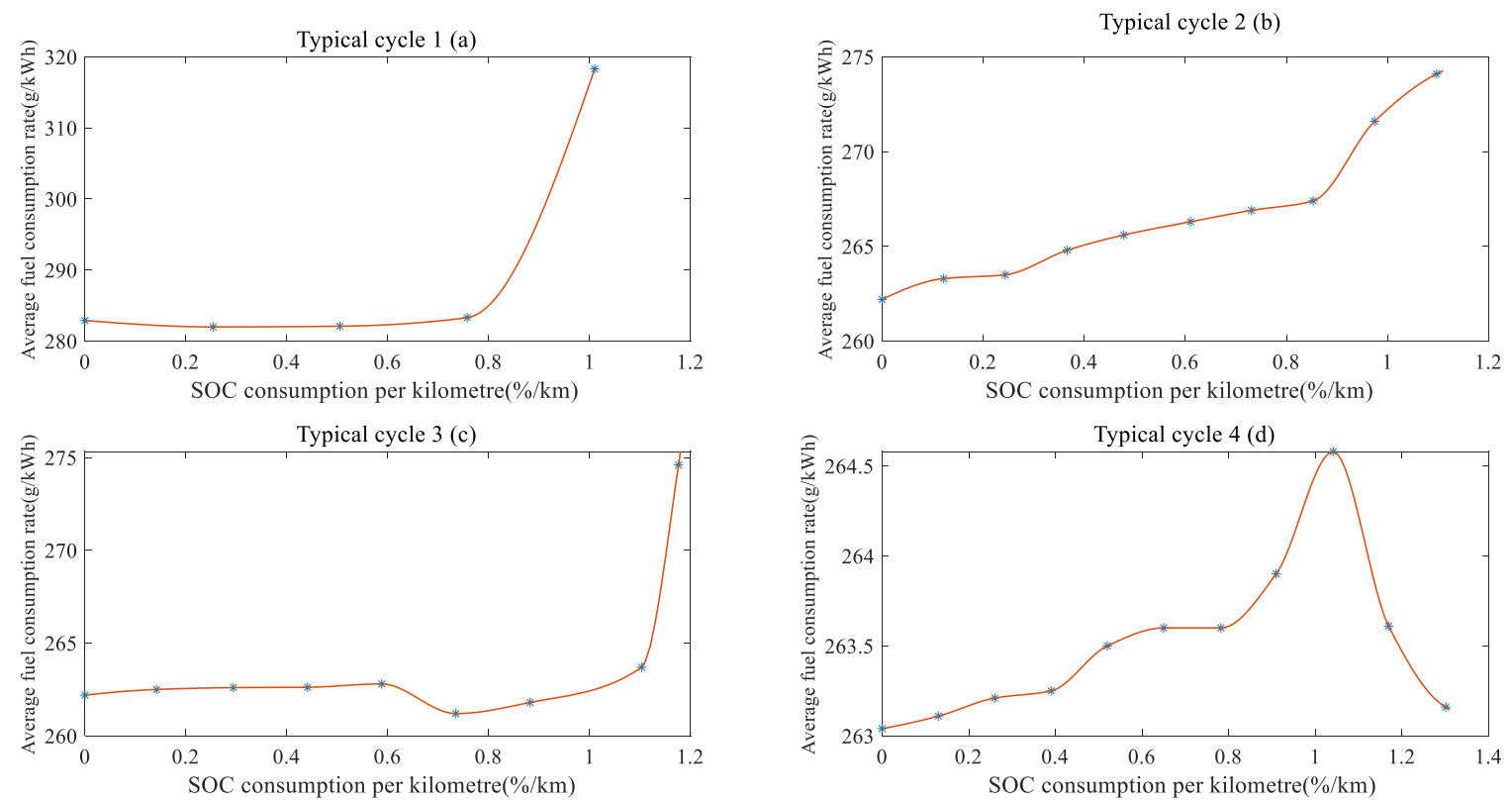

Figure 9. Relationship curve between SOC consumption per kilometer and the average fuel consumption rate under four typical cycles. (a) typical cycle 1 ; (b) typical cycle 2; (c) typical cycle 3; (d) typical cycle 4.

Typical driving cycle 1 refers to driving on crowded roads in urban areas. The vehicle runs at low speed and starts and stops frequently, which is not conducive to engine operation. At the same time, EV mode can fully ensure the dynamic demand of the vehicle. Therefore, in typical driving cycle 1 , the vehicle is driven by motor. Typical driving cycle 2 refers to driving on relatively unobstructed roads in urban areas, with vehicles running at medium speeds and certain start and stop. Therefore, in combination with Figures $8 b$ and $9 b$, the high efficiency area utilization rate of engine should be as high as possible and the average fuel consumption rate should not be too high. The critical upper limit of SOC distribution per kilometer is $0.871 \% / \mathrm{km}$, and $0.853 \% / \mathrm{km}$ is defined as the optimal value of $S O C$ consumption per kilometer $\left(\triangle S O C_{\text {opt_cycle_2 }}\right)$ under typical driving cycle 2. Typical driving cycle 3 refers to driving on unobstructed roads in an urban area, with medium and high speed and less start and stop. In combination with Figures $8 c$ and $9 c$, when the SOC consumption value per kilometer is $1.175 \% / \mathrm{km}$, the utilization rate of engine efficient area is more than $90 \%$, and the average fuel consumption rate is also at the critical point of sudden increase. Therefore, it is most reasonable to select $1.175 \% / \mathrm{km}$ as the distribution upper limit value per kilometer, and $0.735 \% / \mathrm{km}$ is defined as the optimal value of SOC consumption per kilometer $\left(\triangle S O C_{\text {opt_cycle_3 }}\right)$ under typical driving cycle 3 . Typical driving cycle 4 refers to driving on urban expressway road, where the vehicle runs at high speed and rarely starts and stops. In combination with Figures $8 \mathrm{~d}$ and $9 \mathrm{~d}, 1.299 \% / \mathrm{km}$ is selected as the upper limit value of SOC allocation per kilometer.

\subsubsection{SOC Trajectory Planning Algorithm}

Under the given condition of the same electric power and the same mileage, he high efficiency area utilization rate of engine under different typical cycles has obvious difference. Based on this, the mileage and cycle information of the driving route can be obtained through the prediction of the travel characteristics, and then the SOC trajectory 
planning algorithm can be developed according to the SOC requirements of the four typical cycles and the proportion of each travel cycle in the total cycle conditions (Figure 10).

\begin{tabular}{|c|c|}
\hline \multicolumn{2}{|c|}{ If $S \leq S_{e v}$, then driving in battery electric mode all the way; If $S>S_{e v}$, then the following algorithm is executed: } \\
\hline \multicolumn{2}{|c|}{ Recognizing the typical working cycle of the road section } \\
\hline Road section belonging to typical cycle 1 & The SOC allocation value is: $\triangle S O C_{c y c_{-} 1}=\Delta S O C_{E V_{-} c y c_{-} 1} \times S_{c y c_{-} 1}$ \\
\hline Road section belonging to typical cycle 2 & The SOC allocation value is: $\Delta S O C_{c y c_{-} 2}=\Delta S O C_{o p t_{-} y_{c} c_{-}} \times S_{c y c_{-} 2}$ \\
\hline Road section belonging to typical cycle 3 & The SOC allocation value is: $\Delta S O C_{c y c_{-} 3}=\Delta S O C_{o p t_{-} c y c_{-} 3} \times S_{c y c_{-} 3}$ \\
\hline Road section belonging to typical cycle 4 & $\begin{array}{l}\text { The SOC allocation value is: } \Delta S O C_{c y c_{-} 4}=\Delta S O C_{o p t_{-} c y c_{-} 4} \times S_{c y c_{-} 4} \\
\text { Or: } \Delta S O C_{c y c_{-} 4}=\Delta S O C_{t o t}-\left(\Delta S O C_{c y c_{-} 1}+\Delta S O C_{c y c_{-} 2}+\Delta S O C_{c y c_{-} 3}\right)\end{array}$ \\
\hline \multicolumn{2}{|c|}{ If $0 \leq \triangle S O C_{c y c_{-} 4} \leq \triangle S O C_{\max _{-} y c_{-} 4} \times S_{c y c_{-} 4}$, then the distribution is reasonable } \\
\hline \multicolumn{2}{|c|}{ If $\Delta S O C_{c y c_{-} 4}>\Delta S O C_{\max _{-} y c_{-} 4} \times S_{c y c_{-} 4}$, then $\Delta S O C_{c y c_{-} 4}=\Delta S O C_{\max _{-} c y c_{-} 4} \times S_{c y c_{-} 4}$} \\
\hline \multicolumn{2}{|c|}{ Recalculating the SOC allocation value of typical cycle 3 as $\Delta S O C_{c y c_{-} 4}=\Delta S O C_{t o t}-\left(\triangle S O C_{c y c_{-} 1}+\Delta S O C_{c y c_{-}}+\Delta S O C_{c y c_{-} 3}\right)$} \\
\hline \multicolumn{2}{|l|}{ End of SOC trajectory planning } \\
\hline
\end{tabular}

Figure 10. SOC trajectory planning algorithm. Table 4.

The meanings of relevant symbols in SOC trajectory planning algorithm are shown in

Table 4. Relevant meanings.

\begin{tabular}{|c|c|}
\hline Symbol & Meaning \\
\hline$S$ & travel mileage \\
\hline$S_{E V}$ & pure electric mileage under current SOC state \\
\hline$\Delta S O C_{t o t}$ & SOC consumption value of the whole cycle \\
\hline$S_{c y c_{-} i}, i=1,2,3,4$ & mileage of road section under 4 typical cycles \\
\hline$\Delta S O C_{i}, i=1,2,3,4$ & SOC allocation of road sections under 4 typical cycles \\
\hline$\Delta S O C_{E V_{-} c y c_{-} i}, i=1,2,3,4$ & SOC allocation in EV mode under 4 typical cycles \\
\hline$\Delta S O C_{o p t \_c y c \_}, i=1,2,3,4$ & optimal SOC allocation under 4 typical cycles \\
\hline$\Delta S O C_{\text {max_cyc_i } i}, i=1,2,3,4$ & maximum SOC allocation under 4 typical cycles \\
\hline
\end{tabular}

\subsubsection{Verification of SOC Trajectory Planning Algorithm}

For the sake of verifying the rationality, accuracy and effectiveness of the proposed SOC trajectory planning algorithm, the actual driving cycle conditions and identification results in Section 2.2.2 of this paper are used as the driving cycle for verification and compared with the theoretical SOC reference trajectory and the SOC trajectory obtained by DP algorithm (Figure 11).

In Figure 11, the theoretical SOC reference trajectory is close to the SOC trajectory curve obtained based on the DP algorithm. Comparing the SOC trajectory data obtained by the SOC trajectory planning algorithm and the DP algorithm, the maximum error of the SOC trajectory data of the two algorithms is only $3.33 \%$, which shows that the SOC consumption trajectory obtained by the developed SOC trajectory planning algorithm is similar to the optimal SOC consumption trajectory, and the running time is greatly shortened. The rationality, accuracy and effectiveness of SOC trajectory planning algorithm are proved. 


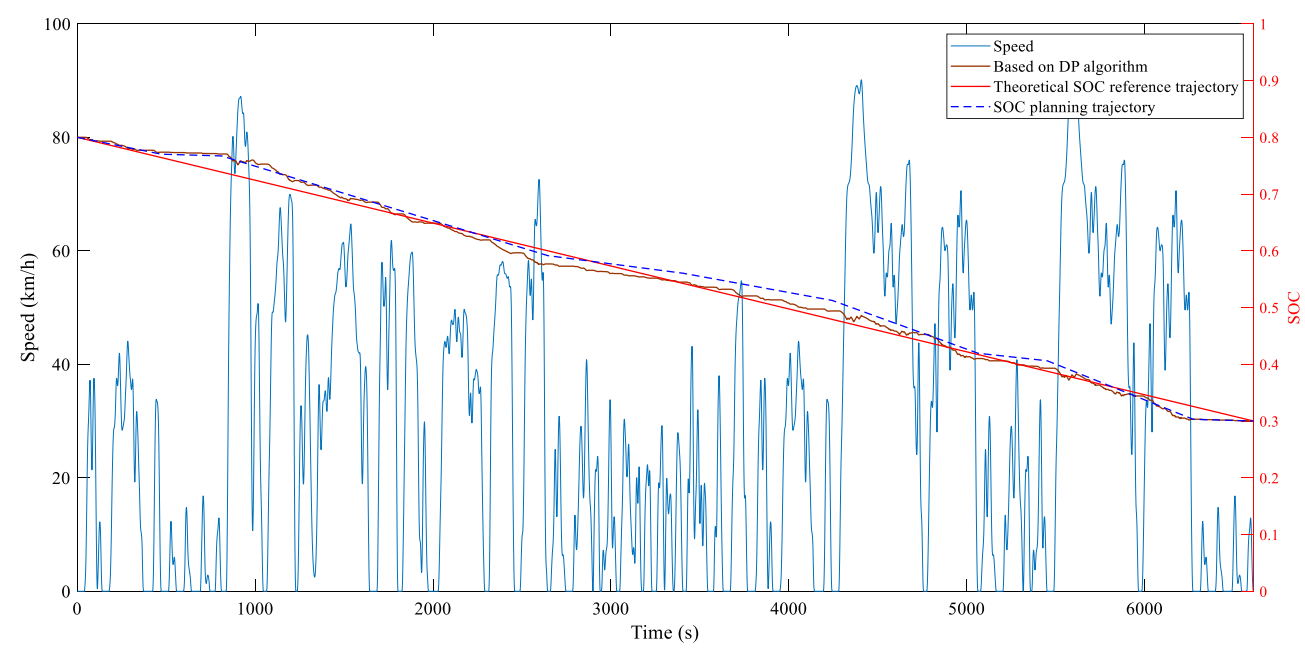

Figure 11. SOC planning trajectory comparison with SOC trajectory based on DP algorithm.

\section{Adaptive Energy Management Method of PHEV Based on Travel Characteristics Prediction}

In order to verify the effectiveness of SOC trajectory planning algorithm based on travel characteristics and study how to use this control algorithm to optimize PHEV energy management, this section will study the energy management method of adaptive equivalent consumption minimization strategy (adaptive ECMS, A-ECMS).

By introducing an equivalent factor, ECMS converts the engine fuel consumption and power battery power consumption into equivalent fuel consumption and takes the minimum equivalent fuel consumption as the optimal control parameter. In ECMS strategy, the equivalent factor is fixed, and it is impossible to complete the global optimization involved in this study under the condition of fixed equivalent factor. The equivalent factor is closely related to travel characteristics and SOC value [34,35]. Therefore, in order to modify the equivalent factor in real time, SOC reference trajectory is introduced to establish A-ECMS.

The cost function of PHEV energy management is shown in Equation (9), aiming at achieving equivalent fuel consumption [36]:

$$
\dot{m}_{e q}(t)=\min \left\{\dot{m}_{f u e l}(t)+s(t) \cdot \frac{P_{b a t}(t)}{H_{l h v}}\right\}
$$

where $m_{e q}(t)$ is the cost function, representing the equivalent fuel consumption of PHEV; $m_{\text {final }}(t)$ is the fuel consumption of the engine; $P_{b a t}(t)$ is the power of power battery; $H_{l h v}$ is the low calorific value constant of gasoline and $S(t)$ is the adaptive equivalent factor.

The equivalent factor correction method based on proportional control and SOC reference trajectory auxiliary correction is adopted to convert the fixed equivalent factor $\mathrm{s}$ into an adaptive equivalent factor $S(t) \mathrm{n}$ this paper, so that the power battery SOC can follow the SOC reference trajectory and reach the target SOC value at the end of the travel cycle. The calculation formula of the adaptive equivalent factor is as follows:

$$
s(t)=s_{0}+K_{p} \cdot\left(\operatorname{SOC}_{r e f}-\operatorname{SOC}(t)\right)
$$

where $S_{0}$ is the initial fixed equivalent factor; $K_{p}$ is the scale factor; $S O C_{r e f}$ is the reference $S O C$ value; $S O C(t)$ is the $S O C$ value at the current time.

For the sake of verifying the accuracy and robustness of A-ECMS based on travel characteristics prediction, this paper obtains another actual driving cycle condition of the driver from the traffic flow and speed information, and takes the actual driving cycle condition as the target cycle to compare and verify the four energy management methods of A-ECMS based on travel characteristics prediction, A-ECMS without prediction, DP and CD-CS. The driver's actual travel cycle condition is shown in Figure 12, the cycle condition 
identification result is shown in Figure 13, the SOC consumption trajectory of different energy management methods is shown in Figure 14, and the A-ECMS torque distribution based on cycle prediction is shown in Figure 15.

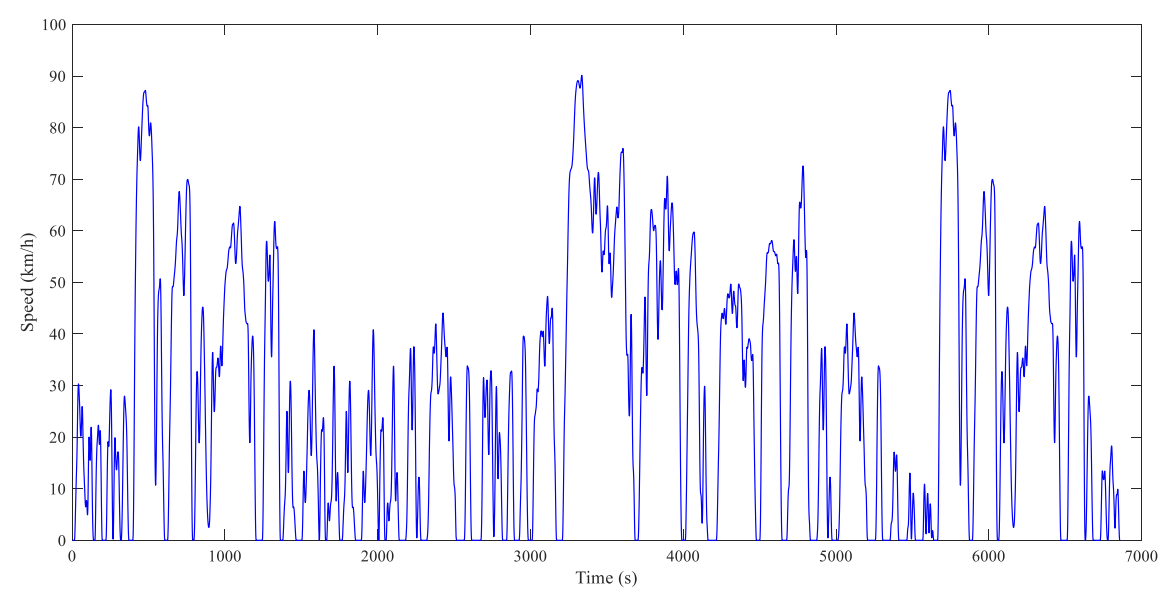

Figure 12. The driver's actual travel cycle condition.

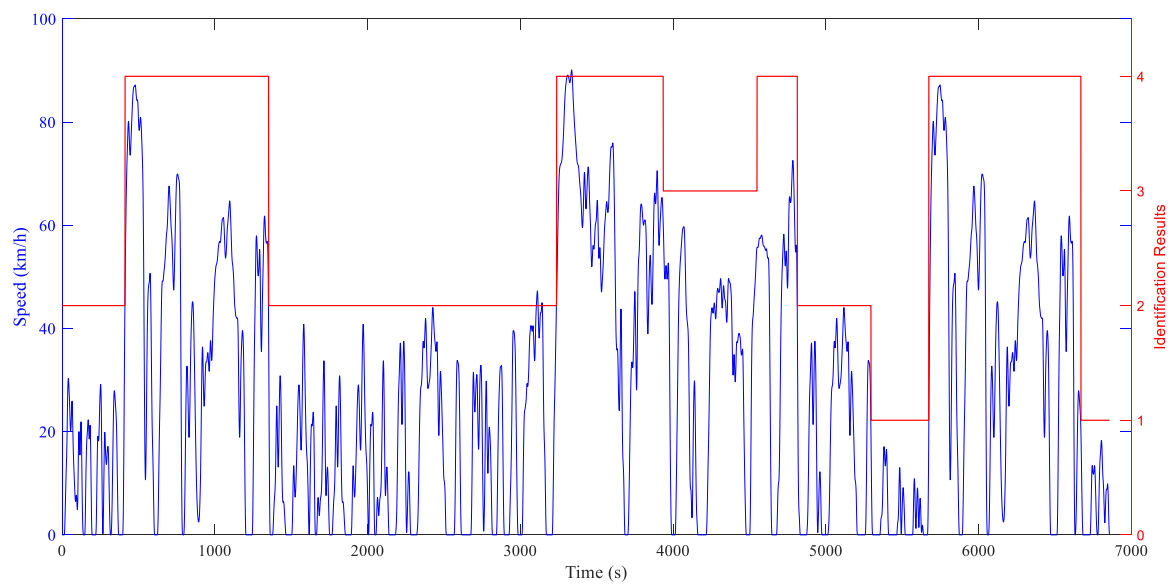

Figure 13. The cycle condition identification result.

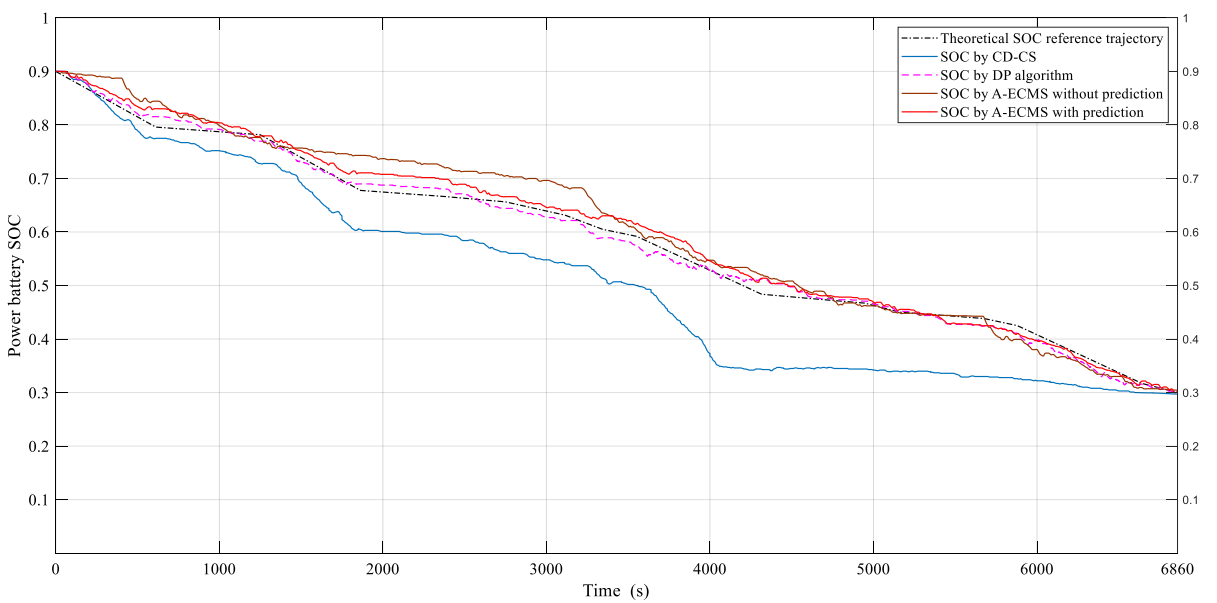

Figure 14. The SOC consumption trajectory of different energy management methods. 

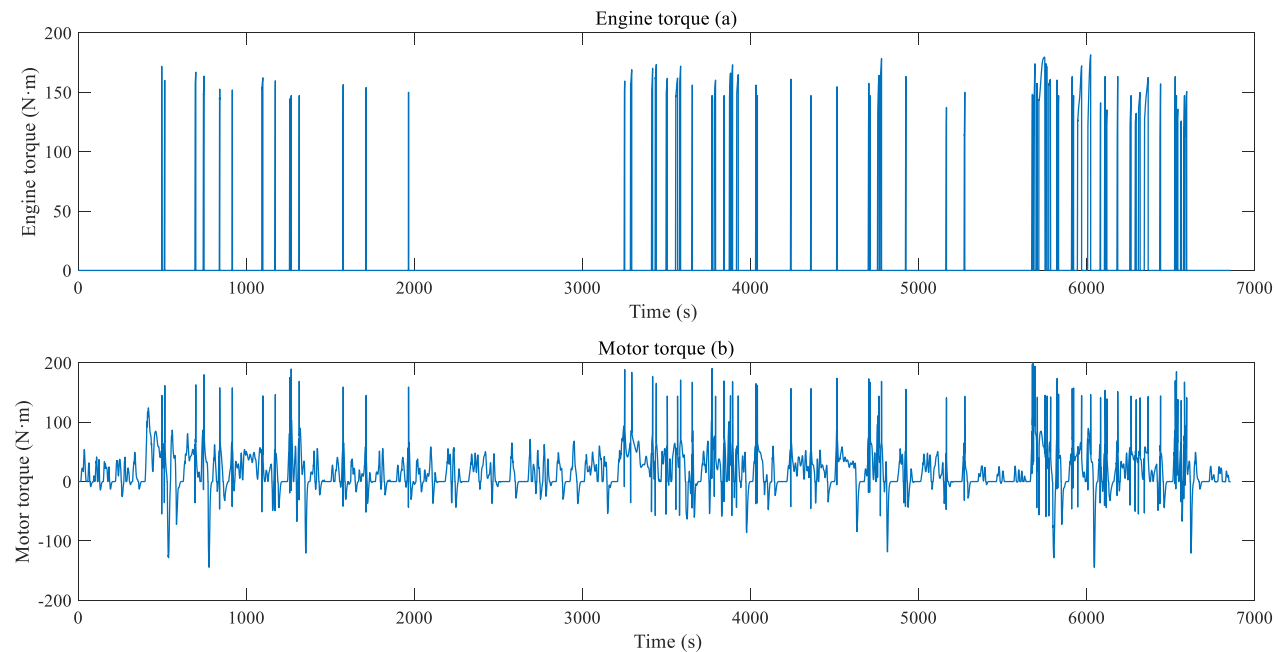

Figure 15. The A-ECMS torque distribution based on cycle prediction. (a) energy torque; (b) motor torque.

In Figure 13, the cycle type identification of the target travel cycles is completed, and the A-ECMS's equivalent factor is modified in real time by combining the cycle prediction and SOC trajectory planning algorithm. Figure 14 shows the SOC consumption trajectory comparison curve of different energy management methods.

The SOC consumption trajectory of A-ECMS energy management method based on travel characteristics prediction is closer to that based on DP algorithm, and can better follow the theoretical SOC reference trajectory. The SOC consumption trajectory of the A-ECMS energy management method without travel characteristics prediction has a great change, and it cannot follow the SOC consumption trajectory based on DP algorithm well, nor can it follow the theoretical SOC reference trajectory well. Table 5 shows the simulation results of different energy management methods.

Table 5. Comparison of simulation results of different energy management methods.

\begin{tabular}{ccccc}
\hline Energy Management Methods & DP & $\begin{array}{c}\text { A-ECMS with } \\
\text { Prediction }\end{array}$ & $\begin{array}{c}\text { A-ECMS without } \\
\text { Prediction }\end{array}$ & CD-CS \\
\hline SOC initial value & & & 0.9 & \\
SOC final value & 0.3000 & 0.3018 & 0.3046 & 0.2942 \\
Fuel consumption (L/100 km) & 2.2468 & 2.3479 & 2.4026 & 2.5788 \\
Savings of fuel economy & $12.87 \%$ & $8.95 \%$ & $6.83 \%$ & $/$ \\
\hline
\end{tabular}

As Table 5 shows, both the DP algorithm and the A-ECMS energy management method based on prediction can better control the SOC final value at the target value, while the non-prediction A-ECMS and CD-CS algorithms are quite different from the target value. Meanwhile, compared with the CD-CS algorithm, the predicted A-ECMS energy management method improves the FE by $8.95 \%$, indicating that when travel distance is higher than the battery electric mileage in current SOC state, the predicted A-ECMS energy management method can use the power more reasonably to obtain better fuel saving effect. The comparison results of simulation experiments verify the rationality and effectiveness of A-ECMS energy management method based on travel characteristics prediction, which is of great help to ameliorate the FE of the PHEVs.

\section{Conclusions}

A PHEV was taken as the research object in this study. Aiming at the problems of difficult comprehensive prediction of vehicle travel characteristics, optimal power distribution and real-time control of PHEV power source, a PHEV energy management method based 
on travel characteristic prediction is proposed to ameliorate vehicle FE and optimization ability. Specifically, the main research contents and innovations of this paper are as follows:

(1) Based on the collection and analysis of a specific driver's driving trajectory data, a method for travel trajectory and mileage prediction, travel condition construction, identification and prediction including clustering the starting point of travel trajectory and mining key points to complete the prediction of travel trajectory and mileage is proposed. The historical travel data is processed, and the target travel cycles predicted by traffic information are considered, and the driving cycles predicted based on traffic information are classified and identified.

(2) For when the driving mileage exceeds the battery electric mileage in the current SOC state, an SOC reference trajectory planning algorithm is established to make the SOC consumption trajectory closer to the optimal trajectory obtained by DP algorithm. For the four typical cycles obtained by the clustering algorithm, the SOC consumption law of different types of typical cycles and the corresponding engine work and fuel consumption are calculated, the SOC distribution law of the four typical cycles is determined, the SOC reference trajectory planning algorithm is formulated, and the rationality, accuracy and effectiveness of the algorithm are verified.

(3) The travel characteristics prediction and SOC reference trajectory planning algorithm are combined and applied to A-ECMS online. The adaptability of equivalent factors of A-ECMS is improved through mileage prediction, condition identification and vehicle speed prediction. The four energy management methods of A-ECMS based on travel characteristics prediction, A-ECMS without prediction, DP and CD-CS are compared and verified. The experiments show that travel characteristics prediction can achieve the goal of rational utilization of power battery power and reducing vehicle fuel consumption.

The proposed PHEV energy management method based on travel characteristic prediction can be used to predict and plan the driver's travel route, so that the drivers no longer have mileage anxiety. Further research will use more technologically advanced equipments for more accurate prediction and real-time energy management.

Author Contributions: Y.M. wrote the paper and provided algorithms; P.W. conceived the structure and research direction of the paper; and T.S. analyzed the simulation results. All authors share first authorship. All authors have read and agreed to the published version of the manuscript.

Funding: This research was funded by the National Key R\&D Program of China, grant number 2018YFB0106200.

Institutional Review Board Statement: This study did not require ethical approval.

Informed Consent Statement: Informed consent was obtained from all subjects involved in the study.

Data Availability Statement: Data available in a publicly accessible repository.

Conflicts of Interest: The authors declare no conflict of interest.

\section{References}

1. Meng, F.-S.; Jin, X.-Y. Evaluation of the development capability of the new energy vehicle industry: An empirical study from China. Sustainability 2019, 11, 2635. [CrossRef]

2. Ma, J.; Liu, X.-D.; Chen, Y.-S.; Wang, G.-P. Current status and countermeasures for Chinas new energy automobile industry and technology development. China J. Highw. Transp. 2018, 31, 1-19.

3. Hamut, H.S.; Dincer, I.; Naterer, G.F. Analysis and optimization of hybrid electric vehicle thermal management systems. J. Power Sources 2014, 247, 643-654. [CrossRef]

4. Croce, A.I.; Musolino, G.; Rindone, C.; Vitetta, A. Estimation of travel demand models with limited information: Floating car data for parameters' calibration. Sustainability 2021, 13, 8838. [CrossRef]

5. Lee, C.H.; $\mathrm{Wu}, \mathrm{C} . \mathrm{H}$. A novel big data modeling method for improving driving range estimation of EVs. IEEE Access 2015, 3 , 1980-1993. [CrossRef]

6. Mangiaracina, R.; Perego, A.; Salvadori, G.; Tumino, A. A comprehensive view of intelligent transport systems for urban smart mobility. Int. J. Logist. Res. Appl. 2017, 12, 664-672. [CrossRef] 
7. Zhu, L.; Yu, F.R.; Wang, Y.; Ning, B.; Tang, T. Big data analytics in intelligent transportation systems: A survey. IEEE Trans. Intell. Trans. Syst. 2019, 20, 383-398. [CrossRef]

8. Liu, Y.-G.; Li, J.; Ye, M.; Qin, D.-T.; Zhang, Y.; Lei, Z.-Z. Optimal energy management strategy for a plug-in hybrid electric vehicle based on road grade information. Energies 2017, 10, 412. [CrossRef]

9. Zhang, C.; Vahidi, A. Route preview in energy management of plug-in hybrid vehicles. IEEE Trans. Control Syst. Technol. 2012, 20, 546-553. [CrossRef]

10. Wang, Q.-P.; You, S.-X.; Li, L.; Yang, C. Survey on energy management strategy for plug-in hybrid electric vehicles. J. Mech. Eng. 2017, 53, 1-19. [CrossRef]

11. Wirasingha, S.G.; Emadi, A. Classification and review of control strategies for plug-in hybrid electric vehicles. IEEE Trans. Veh. Technol. 2011, 60, 111-122. [CrossRef]

12. Padmarajan, B.V.; McGordon, A.; Jennings, P.A. Blended rule-based energy management for PHEV: System structure and strategy. IEEE Trans. Veh. Technol. 2016, 65, 8757-8762. [CrossRef]

13. Zhou, W.; Zhang, C.-N.; Li, J.-Q. A study on comparison between BL and CD-CS optimal energy management strategies for extended range electric vehicles. Automot. Eng. 2016, 38, 1407-1414.

14. Bayindir, K.C.; Gozukucuk, M.A.; Teke, A. A comprehensive overview of hybrid electric vehicle: Powertrain configurations, powertrain control techniques and electronic control units. Energy Convers. Manag. 2011, 52, 1305-1313. [CrossRef]

15. Patil, R.M.; Filipi, Z.; Fathy, H.K. Comparison of supervisory control strategies for series plug-in hybrid electric vehicle powertrains through dynamic programming. IEEE Trans. Control Syst. Technol. 2014, 22, 502-509. [CrossRef]

16. Chen, Z.; Mi, C.C.; Xu, J.; Gong, X.-Z.; You, C.-W. Energy management for a power-split plug-in hybrid electric vehicle based on dynamic programming and neural networks. IEEE Trans. Veh. Technol. 2014, 63, 1567-1580. [CrossRef]

17. Montazeri-Gh, M.; Pourbafarani, Z. Near-optimal SOC trajectory for traffic-based adaptive PHEV control strategy. IEEE Trans. Control Syst. Technol. 2017, 66, 9753-9760. [CrossRef]

18. Xu, L.-F.; Ouyang, M.-G.; Li, J.-Q.; Yang, F.-Y.; Lu, L.-G.; Hua, J.-F. Application of pontryagin's minimal principle to the energy management strategy of plugin fuel cell electric vehicles. Int. J. Hydrogen Energy 2013, 38, 10104-10115. [CrossRef]

19. Tribioli, L.; Barbieri, M.; Capata, R.; Sciubba, E.; Jannelli, E.; Bella, G. A real time energy management strategy for plug-in hybrid electric vehicles based on optimal control theory. Energy Procedia 2014, 45, 949-958. [CrossRef]

20. Feng, T.-H.; Yang, L.; Gu, Q.; Hu, Y.-Q.; Yan, T.; Yan, B. A supervisory control strategy for plug-in hybrid electric vehicles based on energy demand prediction and route preview. IEEE Trans. Veh. Technol. 2015, 64, 1691-1700.

21. Li, Y.-J.; Qi, W.; Wang, C.; Zhang, B.; Lu, Q. Study on extraction algorithm for time-varying equivalent factor of ECMS for parallel hybrid electric vehicle. Automot. Eng. 2021, 43, 181-188.

22. Shen, P.-H.; Zhao, Z.-G.; Zhan, X.-W.; Li, J.-W.; Guo, Q.-Y. Optimal energy management strategy for a plug-in hybrid electric commercial vehicle based on velocity prediction. Energy 2018, 155, 838-852. [CrossRef]

23. Loïc, J.; Rui, D.S.; Daniela, C.; Alan, K.; Luis, L.M. Smart energy management for series hybrid electric vehicles based on driver habits recognition and prediction. Energies 2020, 13, 2954.

24. Zhang, S.; Xiong, R. Adaptive energy management of a plug-in hybrid electric vehicle based on driving pattern recognition and dynamic programming. Appl. Energy 2015, 155, 68-78. [CrossRef]

25. Onori, S.; Tribioli, L. Adaptive pontryagin's minimum principle supervisory controller design for the plug-in hybrid GM Chevrolet Volt. Appl. Energy 2015, 147, 224-234. [CrossRef]

26. Liu, T.; Yu, H.-L.; Guo, H.-Y.; Qin, Y.-C.; Zou, Y. Online energy management for multimode plug-in hybrid electric vehicles. IEEE Trans. Ind. Inform. 2019, 15, 4352-4361. [CrossRef]

27. Laporte, G. What you should know about the vehicle routing problem. Nav. Res. Log. 2007, 54, 811-819. [CrossRef]

28. Croce, A.I.; Musolino, G.; Rindone, C.; Vitetta, A. Route and path choices of freight vehicles: A case study with floating car data. Sustainability 2020, 12, 8557. [CrossRef]

29. Wang, P.Y.; Li, J.-K.; Yu, Y.-B.; Xiong, X.-Y.; Zhao, S.-J.; Shen, W.-S. Energy management of plug-in hybrid electric vehicle based on trip characteristic prediction. Proc. Inst. Mech. Eng. Part D 2020, 234, 2239-2259. [CrossRef]

30. Li, B.R.; Pi, D.C.; Hou, M.R. EP-LSTM: Novel prediction algorithm for moving object destination. IET Intell. Trans. Syst. 2020, 15, 235-247. [CrossRef]

31. Xue, A.Y.; Qi, J.Z.; Xie, X.; Zhang, R.; Huang, J.; Li, Y. Solving the data sparsity problem in destination prediction. VLDB J. 2015, 24, 219-243. [CrossRef]

32. Ma, L.-L.; Fu, Z.-M.; Li, D.W. Energy management strategy of PHEV based on traffic prediction. Comput. Meas. Control 2017, 25, 207-211.

33. Ahmad, M.; Mahyar, V.; Nasser, L.A. Real-time immune-inspired optimum state-of-charge trajectory estimation using upcoming route information preview and neural networks for plug-in hybrid electric vehicles fuel economy. Front. Mech. Eng. 2015, 10, 154-167.

34. Zeng, Y.-P.; Cai, Y.; Kou, G.-Y.; Gao, W.; Qin, D.-T. Energy management for plug-in hybrid electric vehicle based on adaptive simplified-ECMS. Sustainability 2018, 10, 2060. [CrossRef] 
35. Li, Y.; Jiao, X.-H. Real-time energy management for commute HEVs using modified A-ECMS with traffic information recognition. IET Intell. Trans. Syst. 2019, 13, 729-737. [CrossRef]

36. Sun, C.; Sun, F.-C.; He, H.-W. Investigating adaptive-ECMS with velocity forecast ability for hybrid electric vehicles. Appl. Energy 2017, 185, 1644-1653. [CrossRef] 